ISSN: $1130-3743$

DOI: http://dx.doi.org/10.14201/teoredu2014261103118

\title{
LA LITERATURA EMBLEMÁTICA EN UNA EDUCACIÓN UNIVERSITARIA DE CORTE POSMODERNO
}

\author{
Emblematic literature in posmodern higher education
}

\author{
La literature emblématique dans une éducation \\ universitaire pos-moderne
}

\author{
María Paz López-Peláez Casellas \\ Universidad de Jaén. Departamento de Didáctica de la Expresión Musical, \\ Plástica y Corporal. Facultad de Humanidades y Ciencias de la Educación. \\ Campus Las Lagunillas, s/n. 23071 Jaén. Correo-e: mlpelaez@ujaen.es
}

Fecha de recepción: enero de 2014

Fecha de aceptación: abril de 2014

Biblid [(1130-3743) 26, 1-2014, 103-118]

\section{RESUMEN}

El presente artículo tiene como objeto analizar las complejas estructuras semióticas y estéticas presentes en la literatura emblemática de los siglos XVI y XVII y destacar su potencial docente dentro de la educación universitaria, para lo que me centraré en aspectos que considero de especial relevancia en estas formas. En primer lugar, su grado de (dis)conformidad con el saber dogmático de esos siglos, lo que la convierte en un instrumento privilegiado para estudiar posibles (y distintas) interpretaciones de la realidad y su carácter híbrido; esto, a su vez, servirá para enfatizar la necesaria articulación entre discursos y disciplinas que debe ser tenida en cuenta para la comprensión de un hecho en su totalidad. En una segunda sección, destacaré su utilización como recurso didáctico que posibilita el desarrollo de la interdisciplinariedad y del pensamiento creativo, y la práctica de la intertextualidad y de estrategias metacognitivas, además de posibilitar el cuestionamiento del papel del lenguaje en la construcción del conocimiento. 
Palabras clave: literatura emblemática, posmodernidad, educación superior, interdisciplinariedad, creatividad.

\section{SUMMARY}

This paper aims at analyzing the complex semiotic and aesthetic structures constituting the emblematic literature of the $16^{\text {th }}$ and $17^{\text {th }}$ centuries, underlining its potential role as teaching resources within university education. I will especially focus on the basic elements of this corpus: namely, its (dis)agreement with dogmatic knowledge during this period, what makes emblematic literature a privileged vehicle to explore possible (and different) interpretations of reality and the latter's hybrid nature. This will, in its turn, serve to emphasize the necessary cohesion between discourses and disciplines necessary to correctly understand a given fact in its totality. Then, I will concentrate on how emblematic literature can be employed as a teaching resource that enables the development of interdisciplinarity and creative thinking, intertextuality and metacognitive strategies, while it also enables the interrogation of the role of language in the construction of thought.

Key words: emblematic literature, postmodernism, higher education, interdisciplinarity, creativity.

\section{SOMMAIRE}

Le present article s'occupe d'analyser les complexes structures sémiotiques et esthétiques présentes dans la literature emblématique du XVI et XVII siècle, et de souligner le potenciel de l'enseignement dans l'éducation universitaire, pour cela j'essayerai d'axer les aspects les plus essentiels. D'abord le degré de (dés)accords avec les savoirs dogmatiques pendant ces periods, pour devenir un instrument privilégié pour étudier les éventuels (et divers) interpretations de la réalité et sa nature hybride. Cela, à son tour, sert à mettre en valeur l'indispensable cohesion entre les discours et les disciplines nécessaires pour comprendre le fait en tout. D'autre part, je mettrai en relief l'emploi de l'emblématique comme un ressource didactique que permettra le développement de l'interdisciplinarité et le penser créatif, l'intertextualité et les strategies métacognitives, et en outré permet de remettre en question le rôle du langage dans le bâtiment de la connaissance.

Mots clés: literature emblématique, posmodernité, éducation superieure, interdisciplinarité, creativité. 


\section{INTRODUCCIÓN}

Como ya señalara el semiótico ruso-estonio Iuri Lotman, "cada cultura históricamente dada genera un modelo de cultura determinado, inherente a ella" (2000, 168). Aunque es cierto que el concepto de cultura puede tener distintas cargas semánticas, la Cultura, entendida como "raciocinio colectivo" (Lotman, 1998, 41) o como memoria no hereditaria de una colectividad (2000: 172) ${ }^{1}$, se presenta como un sistema sígnico hasta el punto de que ésta es inseparable del lenguaje (y viceversa). Todo esto conduce a que se pueda afirmar que el texto es un elemento imprescindible para el análisis o reconstrucción de una cultura.

Las características formales de la literatura emblemática, por ser los elementos que la componen (tanto la parte textual como la iconográfica) portadores de suprasignificados (al unir al denotativo otro signo connotativo), la convierten en un medio especialmente apropiado para este análisis de la cultura al que me refiero; es un "aparato semiológico para la conquista simbólica de la realidad" en palabras del filólogo Rodríguez de la Flor $(2002,53)^{2}$.

Desde la creación de los emblemas con la publicación del Emblematum Liber de Andrea Alciato en 1531, este género ha actuado como un receptor de las ideas filosóficas, distintas visiones del mundo o valores sociales imperantes en el Renacimiento y Barroco; así, entre otros, el neoplatonismo, neoestoicismo, hermetismo, el principio horaciano del ut pictura poesis, la escolástica o la política de la Contrarreforma (Maravall, 1984). Es a lo que Erwin Panofsky ha denominado el "significado intrínseco o contenido", cuyo análisis resulta crucial en la interpretación de todo producto cultural, y Ernst Cassirer llamó "Valores simbólicos" (Panosfsky, 1989: 23-25, 18). Ambos conceptos hacen referencia a aquellos valores que el artista plasmó en la obra, incluso de forma inconsciente, y que son los causantes de que un artefacto concreto se pueda adscribir a una corriente filosófica, religiosa o a una civilización determinada o, lo que sería lo mismo, por qué razón se eligieron unos motivos y no otros y qué razones subyacen a una presentación concreta. Significa ver los distintos símbolos como elementos integradores de una cultura e íntimamente conectados con ella.

En las siguientes páginas señalaré la idoneidad de la literatura emblemática para ser incluida en el currículo de distintas asignaturas universitarias, dentro de una educación de corte posmoderno. En primer lugar, y atendiendo a su complejidad semiótico-cultural, destacaré varios aspectos: su grado de conformidad con el saber dogmático, lo que la convierte en un instrumento privilegiado para estudiar posibles (y distintas) interpretaciones de la realidad, y su carácter híbrido, dado

1. La cursiva aparece en el original.

2. Se entiende la emblemática como un género con unos límites difusos dentro del que se incluyen formas afines en su estructura, como son las empresas, las divisas y los jeroglíficos, entre otros. Para un análisis de todas ellas (y de sus diferencias), ver RODRÍGUEZ DE LA FLOR (1995). 
que se trata de un artefacto de doble naturaleza icónica (visual) y literaria, lo que servirá para enfatizar la necesaria articulación entre discursos y disciplinas que debe ser tenida en cuenta para la comprensión de un hecho en su totalidad. En segundo lugar, señalaré los beneficios que conlleva su utilización en la educación superior, entre otros: el desarrollo de la interdisciplinariedad y del pensamiento creativo y la práctica de la intertextualidad y de las estrategias metacognitivas. Además, y por tratarse de fuentes primarias, el empleo de la emblemática como recurso docente permite al alumno reflexionar sobre el papel del lenguaje en la construcción del conocimiento.

Como destacaré en último lugar, todo esto convierte a la literatura emblemática en un recurso didáctico de primer orden para explicar de manera práctica al alumnado universitario cuestiones relevantes de la historia del pensamiento dotándole de contenidos humanísticos en una época en la que éstos parecen no gozar de demasiada estima por parte de las instituciones.

\section{COMPLEJIDAD SEMIÓTICA Y ESTÉTICA DE LOS EMBLEMAS}

La unión de la imagen y el texto que, en la mayoría de los casos, integran el emblema, lo erigen como un ejemplo perfecto del ut pictura poesis al que se refiriera Horacio en el Arte Poética y los presentan como un ejemplo de "heterogeneidad de los recursos de la expresividad artística" (Lotman, 2000, 82). En estas formas interaccionan lenguajes codificados de manera diferente, al combinarse signos que son palabras (mote, epigrama y/o comentario), con signos icónicos (pictura); o, utilizando terminología procedente de la semiótica, "signos discretos" -que están separados unos de otros y se caracterizan por tener un significado estable- con "no discretos" - cuyos signos son imposibles de separar (Lotman, 2000, 83) y en los que produce un isomorfismo entre el objeto representado y la representación-. Esta naturaleza híbrida fuerza la necesidad de una doble descodificación por parte del lector que sólo se podrá realizar de manera correcta mediante la interacción del texto y la figura y en muchos casos aportando sus contenidos mentales a los ya representados (Rodríguez de la Flor, 1995). Tampoco se puede olvidar la frecuente presencia de símbolos y su pluralidad de significados en la emblemática. Hacia esta circunstancia ya advirtió Gombrich al hablar de la "falacia del diccionario", o el peligro de considerar la existencia de un "código con una relación biunívoca entre signo y significación" (1983, 23-24).

Toda esta complejidad semiótica y estructural inherente a la emblemática se ve acrecentada por la naturaleza ideológica del discurso que desarrolla. Aunque ciertamente existen diferencias entre los emblemas realizados en distintos países, en general (y especialmente en los de cultura católica), se reprodujo un sometimiento a las verdades de la fe y la emblemática siguió anclada, en buena medida, en mapas conceptuales propios del Medievo. El pensamiento se articuló frecuentemente en torno a las cuatro similitudes - la convenientia, la aemulatio, la analogia y la simpatia-, al simbolismo o a la consideración del mundo como un mensaje 
cifrado (Foucault, 1991). Está de más decir que este discurso inclinado hacia las interpretaciones herméticas se oponía diametralmente al método científico que empezaba a desarrollarse en algunos países de Europa. En muchos de estos libros queda constancia de un incipiente enfrentamiento entre el saber tradicional y la nueva ciencia experimental, entre la sapiencia y la sciencia, entre la elucubración mental y la causalidad y el empirismo (Maravall, 1984).

\section{LA LITERATURA EMBLEMÁTICA EN UNA EDUCACIÓN POSMODERNA}

¿Puede un género literario que estuvo en boga en los siglos XVI, XVII y XVIII convertirse en un recurso didáctico en el siglo Xxi? ¿Cómo se puede vincular este complejo género literario a una educación de corte posmoderno? ¿Qué beneficios puede generar su utilización? A estas cuestiones intentaré responder en las siguientes páginas.

Antes que nada, si pretendo defender la utilización de la emblemática como herramienta didáctica en el currículo, debo comenzar recordando que este empleo no es, ni mucho menos, novedoso sino que está vinculado casi a los mismos orígenes del género. Tras los primeros libros, que se caracterizaron por el oscurantismo y la sutileza intelectual (y que, como consecuencia, estaban destinados tan sólo a unos pocos), los publicados durante el siglo XVII contenían principios morales y religiosos que los convirtieron en un recurso utilizado en la educación (Sebastián, 1995). Así lo consideraron los jesuitas, que los incluyeron en su famoso plan de estudios -la Ratio Studiorum-, y dentro de los cursos de retórica, por considerar que "favorecían el ingenio y la invención" (Sebastián, 1995, 15). Tampoco se puede olvidar la importante presencia que tuvieron estos libros dentro de la educación de los príncipes -los denominados espejos de príncipes- en donde se presentaban como encarnación del utile dulci al que se refiriera Horacio en el Arte Poética (v. 343).

A pesar de estos antecedentes en la educación, la literatura emblemática no ha sido utilizada en la enseñanza en, aproximadamente, los últimos doscientos años, excepto en ocasiones muy aisladas ${ }^{3}$ y en ningún caso (hasta donde tengo conocimiento) haciendo referencia a su potencial docente en una gran parte de

3. En España hay que destacar la defensa que realiza Beatriz ANTón de la utilización de este género en los estudios latinos ("Emblemática y didáctica del latín", en Revista de estudios latinos, 2002, 2, 199-233), o la tesis doctoral El lenguaje ideográfico: una metodología de la enseñanza de las ciencias sociales en la EGB, en la que su autora, María Carmen Redondo Benito DE VALLe, se refería de manera superficial a ese poder didáctico de los emblemas en una disciplina concreta. Más ambicioso es el proyecto originado en la Universidad de Utrecht que consiste en un repositorio de emblemas holandeses de temática amorosa realizado por alumnos y en el que se puede participar mediante un juego de preguntas y respuestas: en http://emblems.let.uu.nl/emblems/educational/ home.html. 
las disciplinas universitarias. La gran variedad de contenidos de la emblemática la convierte, como me ha demostrado mi experiencia en los últimos años ${ }^{4}$, en un marco perfecto para desarrollar desde la Universidad una perspectiva interdisciplinar desde parámetros de disciplinas tan dispares como la Historia (ya sea del Arte, de la Música, de la Política o del Derecho), la Filología (Clásica y Moderna), la Lengua o la Didáctica. Pero no sólo puede estar integrada en el currículo de las disciplinas que conforman los estudios humanísticos, sino que también puede hacerlo en un abanico de titulaciones mucho más amplio. Si se tienen en cuenta los beneficios que su complejidad estructural y semiótica pueden producir en el desarrollo del pensamiento creativo, divergente e inductivo, tan importantes en la sociedad en la que vivimos, o en las destrezas de investigación y cognición, las posibilidades que se ofrecen son mucho mayores: ¿por qué no ser incluida entonces en los estudios de Derecho (y no restringida a la Historia del Derecho), de las Matemáticas o de la Física? Además, en todos los casos y gracias a esa interdisciplinariedad inherente a los emblemas, los alumnos podrán comprender que todos los procesos humanos están interrelacionados, forman parte de una cultura unitaria y compleja, independientemente de que puedan estudiarse por separado. Se trataría, mediante este recurso, de "reconocer y aprehender la complejidad de lo real" (Morin, 1995, 28).

\subsection{Emblemas y posmodernidad}

Como ya he apuntado, en la literatura emblemática renacentista y barroca se ponen de manifiesto algunos de los axiomas sobre los que descansa la teoría posmoderna. Así, se puede resaltar la consideración del conocimiento como una interpretación -de las muchas que se pueden hacer- de la realidad y, unido a lo anterior, la estrecha y profunda conexión entre la episteme y el contexto social y cultural en el que se desarrolla o el papel del lenguaje en la construcción del conocimiento. Como es sabido, la posmodernidad postula la no existencia de una razón objetiva. El conocimiento científico se construye a partir de mapas conceptuales en los que juega un papel decisorio el discurso hegemónico y es tan sólo una interpretación que es compartida por un grupo de personas (Efland y otros, 2003). La construcción que se hizo de la realidad en Occidente es, por tanto, sólo

4. Desde hace cinco años coordino un Proyecto de Innovación Docente que utiliza la literatura emblemática como recurso docente en los estudios universitarios. Este proyecto, en el que participan profesores de las Universidades de Granada, Salamanca, Coventry (Gran Bretaña) y especialmente de la Universidad de Jaén, fue galardonado en 2010 por esta última universidad, que valoró su elevado grado de innovación y los beneficios que su puesta en práctica proporcionaba al alumnado. Los trabajos realizados por los alumnos dentro del proyecto han sido publicados por la Universidad de Jaén en, hasta el momento, cuatro volúmenes. Recientemente el proyecto ha recibid o una reseña en la Society for Emblem Studies Newsletter (2013, 23-25). 
una de las muchas (y diferentes) que se podrían haber realizado (Aronowitz y Giroux, 1991).

Partiendo de la premisa de que, como señalara Panikkar, el conocimiento objetivo de la realidad es sólo un "mito" (Laudo, 2011), se debe cuestionar la idea de que el conocimiento está exento de categorías y valores; que las creaciones humanas son algo abstracto, que están despolitizadas y que no tienen relación con el contexto. Resulta prioritario recordar que cada cultura escoge los hechos que quiere que sean recordados, selecciona aquellos que serán convertidos en "elementos de texto" y olvida otros que pasan a ser inexistentes (Lotman, 2000, 174). En palabras de Aronowitz y Giroux, "not only makes visible the ways in which domination is being prefigured and redrawn, it also points to the shifting configurations of power, knowledge, space, and time that characterize a world that is at once more global and more differentiated" (1991, 115). Esta fragilidad epistemológica de la historia hace que haya que preguntarse: «No se logra la unidad al precio de olvidar todo lo que contradice esa unidad?" (Lotman, 2000, 114).

En la literatura emblemática se demuestra de manera fehaciente que la epistemología es inseparable del contexto social y cultural. De manera más concreta, y dicho de otro modo, la lectura cristiana del mundo que se realiza, por ejemplo, en la emblemática española (y que es un fiel reflejo de la época) es incompatible con la adopción de un método que no fuera especulativo y que no se basara en la metafísica. Así lo hace Andrés Ferrer de Valdecebro en su Gobierno General, Moral, y Politico ballado en las fieras, y animales silvestres, sacado de sus naturales propiedades, y virtudes, con particular tabla para sermones varios de templo, y de santos (Barcelona, 1696), en el que una lectura de cualquiera de sus capítulos pone de manifiesto la prevalencia de los tópicos medievales, a saber: interpretaciones herméticas regidas por la teoría de los cuatro sentidos alegóricos o la utilización de la naturaleza como código semiótico.

Como consecuencia, el conocimiento que se nos ha transmitido en este género literario es un constructo de la realidad fuertemente influido por la subjetividad y el entorno cultural en el que nada puede tener el rango de "universalización racionalmente admisible" (Laudo, 2011, 51). ¿Cómo si no se podría explicar el emblema de Henry Peacham que tiene como mote "Hibernica Respub" -incluido en Minerva Britanna or a Garden of heroical devises (Londres, 1612)-, en el que Irlanda (por boca de un arpa) da las gracias al rey Jacobo I por su sometimiento y se afirma que los irlandeses están agradecidos por la llegada de los ingleses?, o ¿cómo se convirtió en un loci commune la identificación de monarcas absolutos con instrumentistas que consiguen crear una música armoniosa gracias a la colaboración voluntaria del pueblo? [Fig. 1] .

5. El emblema de Juan de Solórzano Pereira que incluyo forma parte de los Emblemas regio políticos (Valencia, 1658-1660). Reproduzco la pictura (o grabado) del emblema y, dentro de ella, el mote colocado a modo de orla ("Temperandum prius quam puniendum", es decir, "Templar, o afinar, 


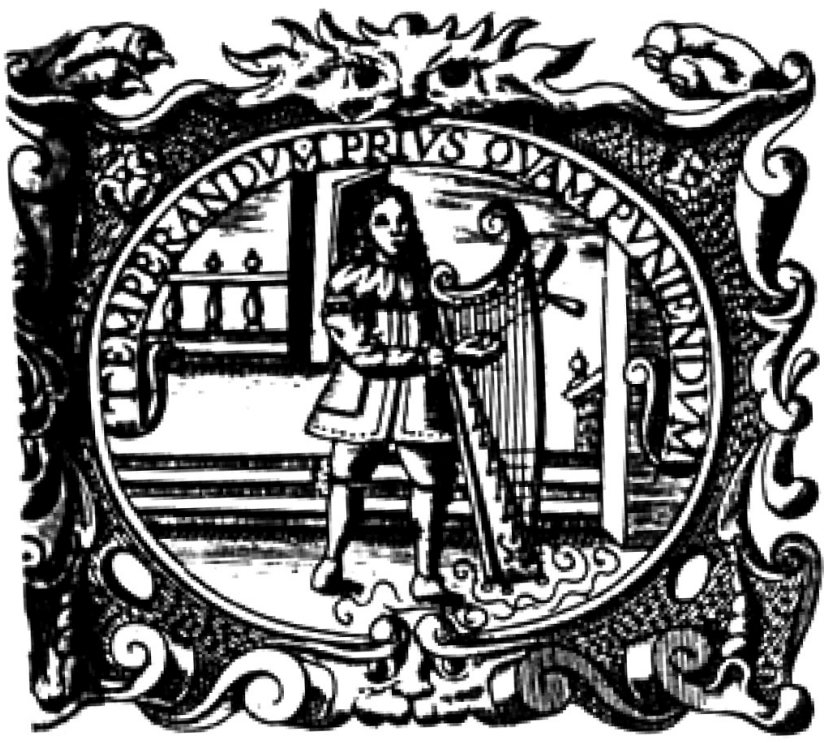

Fig. 1. Juan de Solórzano Pereira, Emblemas regio políticos (Valencia, 1658-1660).

En ambos casos, como en tantos otros, se ofrece una interpretación falaz de la realidad, olvidando, en el primer caso, la sangre vertida por los irlandeses y que la anexión de Irlanda no fuera pacífica, y en el segundo, el hecho de que se tratara de un gobierno en el que el pueblo no tenía ningún poder de actuación o decisión. Estos ejemplos nos recuerdan que, repetidamente a lo largo de los siglos, ha habido voces silenciadas y pueden ayudarnos a imaginar cuál pudo haber sido esa "otra" historia: la de los sometidos y oprimidos a causa de su color, clase social, etnicidad, sexo o nivel económico. Es a lo que el sociólogo Boaventura de Sousa Santos denomina la "sociología de las ausencias", con la que se refiere a todo lo que "se convierte en ausente al ser suprimido, desacreditado, descalificado, marginado, en resumen, por quedar fuera de las monoculturas epistemológicas y sociales" (Dale y Robertson, 2007, 57).

Todo esto sirve además para mostrarnos el importante papel que desempeña el autor en la obra (y en la construcción del conocimiento) y cómo su subjetividad

\footnotetext{
antes de castigar"). En el extenso comentario que completa el emblema puede leerse: "(t)ambién es armonía la de una República, en que, como las cuerdas en aquel instrumento, tiene cada ciudadano su lugar y puesto. Si acaso alguno disuena y ocasiona con alguna culpa desapacible consonancia, el Príncipe, que es como el Maestro de Música, no ha de cortar luego la cuerda; témplela primero, redúzcala a concordia" $(1658,590-591)$.
} 
queda impresa en ella con fuerza. En los ejemplos anteriores, Henry Peacham (en el primero de ellos) o Juan de Solórzano, Diego Saavedra Fajardo y Juan Baños de Velasco (en el segundo, como autores que utilizaron el mencionado loci commune) tenían una estrecha relación con la monarquía: la de Jacobo VI y Felipe IV, respectivamente. Deben, por tanto, cuestionarse los grandes relatos que se han construido, y que pueden estar construyéndose, sobre la realidad. Siguiendo a Lyotard, debe primar la "incredulidad con respecto a los metarrelatos" (Lyotard, 1991, 4), y esto debe traducirse en un acercamiento al autor a través de un análisis de sus características personales (raciales o étnicas, de género, ideología o clase social).

Ejemplos como los señalados sirven para explicar que la historia es un constructo personal que está influido no sólo por el autor y su entorno, sino también por el lenguaje empleado, hasta el punto de que este último no nos permite ver el mundo como realmente es (Yilmaz, 2010). Resulta necesaria la deconstrucción de los textos como forma de llegar a su sentido último y así analizar no sólo cómo están estructuradas las partes, sino también qué poderes subyacen en los discursos (Rorty, 1993). Con la utilización de la literatura emblemática como recurso didáctico en los estudios universitarios se puede cuestionar la naturaleza ideológica del conocimiento que ha llegado hasta nosotros, lo que constituye un primer y necesario paso para cuestionarnos el conocimiento que nos rodea y nos hace llegar los medios de comunicación.

El otro aspecto que quiero mencionar en esta defensa de la utilización de la literatura emblemática en la educación de la era posmoderna tiene que ver con la metodología y las estrategias docentes. En este proyecto sobre literatura emblemática, cada uno de los profesores pretende conducir su práctica docente de manera que, siguiendo a Carr (1995), refleje los ideales educativos emancipadores, parta de la autorreflexión y desarrolle en el alumnado un espíritu crítico que le haga cuestionarse cualquier discurso. Se apuesta por combinar la creencia modernista en la capacidad de las personas para usar la razón crítica con la preocupación posmoderna de hacerlo en un mundo caracterizado por una pluralidad de narrativas y en el que se rechaza la creencia en la existencia de un narrador objetivo y legitimado (Aronowitz y Giroux, 1991).

Siguiendo a Terrén, se considera que no se puede encontrar

un diseño universalmente válido del conocimiento en el que se exprese un consenso generalizado acerca del saber que deba ser administrado como legítimo y acerca de la forma en que esta administración deba realizarse ${ }^{6}(1997,126)$.

Por eso, en este proyecto se ha privilegiado la voz del estudiante, pero haciéndole ser consciente en todo momento de que el suyo es sólo uno de los discursos posibles. Del mismo modo, se han utilizado unos métodos pedagógicos caracterizados por el

6. La cursiva de la cita aparece en el original. 
relativismo (por cuanto se adecuan a las distintas situaciones) y encaminados a preparar a los estudiantes para habitar en «un mundo con verdades, valores y gustos relativos" (Laudo, 2011, 56). La metodología del proyecto ha orbitado por tanto en torno a lo contingente pero basándose en un "relativismo no ingenuo", es decir, un relativismo que reconoce "un límite a la validez de sus afirmaciones, pero que, dentro de ese ámbito en el que queda recortada la validez de su discurso, [acepta que] una afirmación verdadera o un valor compartido lo son de modo lógicamente absoluto" (Laudo, 2011, 56).

Como recordara Chávez (2006), en nuestro sistema educativo hay muy poco conocimiento reflexivo-complejo y las clases se suelen reducir con demasiada frecuencia a la exposición de contenidos-verdades por parte del profesor y a la recepción pasiva del alumno sin que se fomente el interés por la investigación ni la curiosidad por aprender. No se desarrolla la imaginación ni las facultades críticas y todavía está muy presente en nuestras aulas la "pedagogía de la memorización" (Nussbaum, 2012, 178), la "concepción bancaria" de la educación a la que se refiriera Freire en su seminal Pedagogía del Oprimido (1975). Frente a esto, y como ya he apuntado, el empleo de los emblemas como recurso didáctico resulta beneficioso ya que potencia la interdisciplinariedad, la metacognición, la intertextualidad y el pensamiento creativo, divergente y crítico. Un trabajo individual sobre los emblemas posibilita que el alumno siga su propio ritmo de aprendizaje y no lo homogeneiza al resto. Además, al no existir una única respuesta (debido a la pluralidad de significados que contienen), se respetan las diferencias en los resultados dentro de un marco de coherencia básico. Cualquier significado puede ser válido siempre que está bien argumentado y razonado.

Como es sabido, la cultura se apoya en un sistema de signos interrelacionados, por lo que para su estudio es necesario trabajar una metodología educativa y unas herramientas que sean acordes a ella y capaces de superar la rigidez de los modelos disciplinarios. Sin embargo, en la escuela se siguen manteniendo las directrices de una educación propia de la Modernidad y no se transgreden los límites establecidos entre disciplinas. Se mantiene una secuenciación de contenidos basada en las ideas de control, de orden y, especialmente, de complejidad (Terrén, 1997). No se aborda la representación del conocimiento como un constructo social sino que se opta por la fragmentación de los distintos ámbitos de la realidad (Efland y otros, 2003) sin tener en cuenta que esta parcelación dificulta su percepción, comprensión e interpretación, provoca que se ofrezca una visión no veraz de la realidad y ocasiona disfunciones para la comprensión de las relaciones entre las disciplinas. Como consecuencia de todo esto, son muchos los investigadores que desde hace años han destacado la importancia de que en el currículum estén presentes planteamientos interdisciplinares o transdisciplinares. Es el caso de Moraes, que aboga por la generación de «nuevos ambientes de aprendizaje, en el que el ser humano [sea] comprendido en su multidimensionalidad como ser indivisible en su totalidad" (2005, 17-18) o de Terrén, cuando se refiere a la reconceptualización de 
los contenidos curriculares y a la creación de un discurso educativo que no esté sujeto a ninguna metanarrativa (1997).

La literatura de emblemas pone de manifiesto, a través de su naturaleza híbrida y de su complejidad implícita, la necesaria articulación entre discursos que debe realizarse para la comprensión de un artefacto cultural en su totalidad. Como se ha señalado, este género alcanzó una gran relevancia en la cultura barroca gracias a su presencia en la poesía, el teatro, las representaciones de arte efímero o la pintura. Es por ello por lo que para comprender buena parte de las manifestaciones artísticas de estos siglos hay que volver los ojos a la emblemática. Sólo a través de ella, y superando la disciplinariedad considerada mayoritariamente en nuestro sistema educativo como única estructura de conocimiento, podremos comprender artefactos tan dispares como la pintura de Johannes Vermeer; la serie Los desastres de la Guerra de Francisco de Goya; las referencias humanísticas que están presentes, entre otros, en la obra de Velázquez, en los autos sacramentales de Calderón y en los dramas de Shakespeare; o algo mucho más próximo a nosotros como es la simbología fascista o la utilizada en algunos anuncios publicitarios ${ }^{7}$.

El género de la literatura emblemática es muy útil no sólo en este sentido sino también en otro que considero primordial: dota al alumnado de contenidos humanísticos, en una época (tanto la actual como la que desgraciadamente se avecina) en la que éstos están perdiendo todo el apoyo institucional. Ausencia ésta que, para Nussbaum, producirá "generaciones enteras de máquinas utilitarias, en lugar de ciudadanos cabales con la capacidad de pensar por sí mismos, poseer una mirada crítica sobre las tradiciones y comprender la importancia de los logros y los sufrimientos ajenos" $(2012,20)$. Los emblemas no sólo pueden ayudar a recuperar y desarrollar este maltrecho "espíritu de las humanidades" (Nussbaum, 2012, 26). $\mathrm{Y}$ es que descodificar un emblema se presenta como una actividad compleja en la que deben intervenir disciplinas humanísticas que, lamentablemente, no están interconectadas en nuestro sistema educativo. En cualquiera de ellos se encuentran referencias procedentes de la historia (tanto real como mitológica), del arte, de la filosofía, de la política o de la lingüística.

A la gran cantidad de códigos "que se entrecruzan en una cultura [y que] nos demuestran que incluso el mismo mensaje se puede descodificar desde distintos puntos de vista y recurriendo a diversos sistemas y convenciones" (Eco, 1986, 112), hay que añadir la que se origina en un género que ya es polisémico de por sí. Es a esta multiplicidad de interpretaciones de una realidad siempre compleja a la que se refiere Bernat Vistarini cuando señala que el libro de emblemas «inventa y desarrolla un modo autónomo de lectura [y] traza una línea a partir de la cual otros hábitos de lectura sólo sirven secundariamente" (1998, 238). Este elevado

7. Para no convertir esta cita en un listado farragoso de referencias, remitimos a una página web elaborada por Sagrario López Poza en la que se recogen algunas de las publicaciones más relevantes que se han realizado en el campo de la emblemática: http://www.bidiso.es/emblematica/repertoires.html. 
grado de signicidad potencia el desarrollo de una actitud creativa, tan importante en la compleja época en la que vivimos. Ya que los problemas tienen más de una causa, también deben tener más de una solución y es el pensamiento creativo y divergente el que ayuda a encontrarlos. Como señalara con gran agudeza Roy, "Societal problems do not, at least nowadays, come in discipline-shaped blocks" (Petrie, 1992, 312). Este pensamiento creativo cuestiona nuestra forma de pensar, se opone a la repetición, a la inercia, a la continuidad y "abre la puerta a la aparición de respuestas imaginadas" (Pérez, 2009, 190).

Esta reinterpretación del discurso que se presenta en los emblemas es principalmente una labor de (re)creación. Para descifrar el significado oculto que transmiten no sólo hay que asociar ideas, sino también descodificar metáforas y descubrir enigmas, posibilitando un ejercicio de intertextualidad, de búsqueda de interrelaciones entre el emblema y otros textos. Pero, como recuerda Montalvo (citando a Wujec), "(1)as metáforas -y sus parientes, los símiles, las analogías, los paralelismos, las alegorías, los símbolos, las alusiones- son mucho más que figuras retóricas. Son las artífices de nuestro sistema conceptual; construyen andamios de ideas» (2011, 124). Según esto, además de servir para buscar relaciones dialógicas, los emblemas, utilizados como estrategia docente, potenciarían el desarrollo del pensamiento creativo y lógico, que, como señalan Carbonero y Coromoto, son componentes esenciales para el aprendizaje, entre otras disciplinas, de las matemáticas (2006).

Ya para finalizar, el empleo de este recurso didáctico posibilita, como se puede deducir de lo expuesto, la utilización del método heurístico, es decir, del aprendizaje por descubrimiento. Con él no sólo se consigue una mayor motivación por parte del estudiante y un desarrollo de las destrezas de investigación -una de las competencias más importantes en la enseñanza, sobre todo en la universitaria-, sino que lo acaba convirtiendo en un agente independiente. Serán los alumnos los que, al trabajar con los emblemas, decidan qué quieren aprender, cuándo y cuánto y el profesor se limitará a seguir el camino trazado por ellos, a resolver sus dudas cuando las haya de manera personalizada, bien en tutorías individuales, bien en pequeño grupo. Este método heurístico se desarrolla como una suerte de aprendizaje dialógico -opuesto a la "colonización tecnocrática del aprendizaje" (Flecha y Tortajada, 1999, 22)- y de aprendizaje por integración, al cuestionarse por el significado último de la investigación (Gordon, 2007). En otras palabras, el objeto de este proyecto es, recordando a Masschelein, mantener "abiertos espacios y tiempos donde otros significados puedan ser pensados y articulados" (Laudo, 2011, 59).

\section{COnClusiones}

La crisis del modelo cientifista, positivista y reduccionista y la aparición de un nuevo paradigma posmoderno (de la complejidad) a finales del siglo xx han tenido, como es bien sabido, importantes consecuencias en el pensamiento y, por ende, en la educación. La labor del profesor debe ser, según este nuevo modelo, 
la de enseñar a pensar al alumno en lugar de llenar su cabeza de datos ya que, en educación, es más importante la calidad que la cantidad (Morin, 1999). No podemos seguir enseñando de la forma a la que se refiere Guillaume Guirault en el emblema que tiene como mote "On doit bien instruiré les enfans en ieunesse" [ Se debe enseñar bien a los jóvenes en la juventud»] ${ }^{8}$ en el que se compara el acto de educar al de llenar un cántaro y en el que joven alumno actúa como un mero receptor de conocimiento [Fig. 2] reflejando el concepto de "educación bancaria" de Freire (1975). La educación del siglo XXI debe apoyarse en la pluralidad metodológica e intentar evitar que todo el peso recaiga en la tradicional clase magistral. Debe cuestionarse los mecanismos educativos propios del modernismo y frente a las cabezas bien llenas (a modo de cántaros), crear "cabezas bien puestas", utilizando la terminología de Edgar Morin (1999).

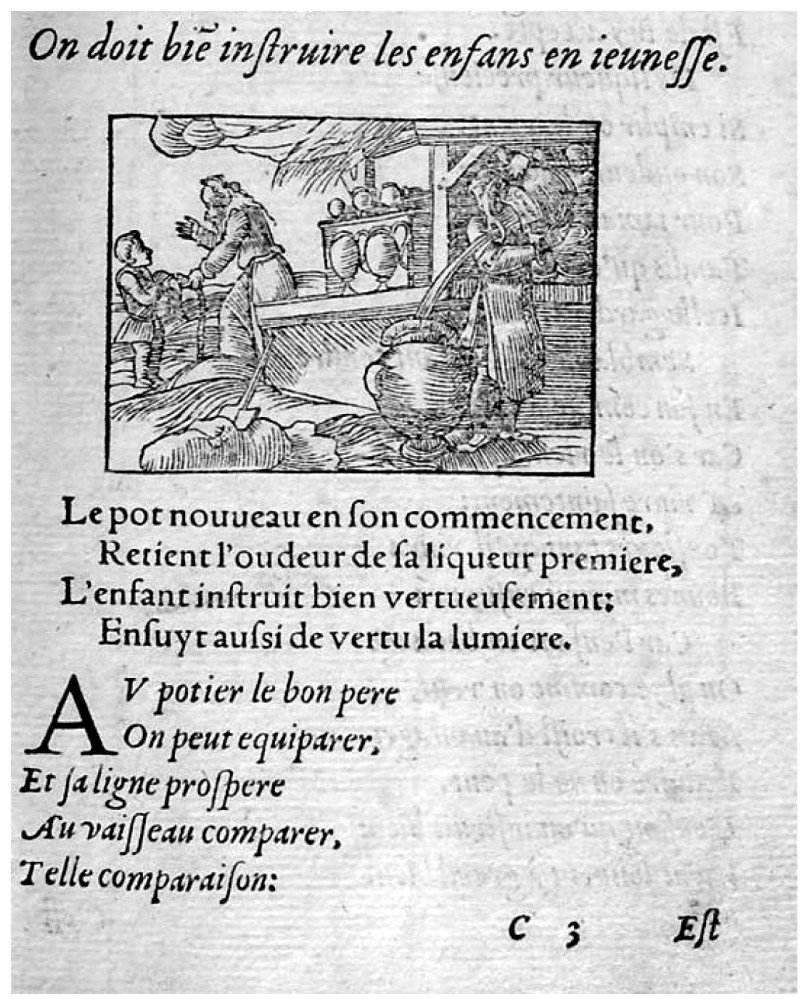

FIG. 2. Guillaume Guirault, Le premier libre des emblemes (Lyon, 1550).

8. Traducción de la autora. Este emblema está incluido en Le premier libre des emblemes (Lyon, 1550). 
A través de la literatura emblemática se articulan discursos que son cruciales para comprender los siglos XVI y XVII -no sólo éstos, aunque sí principalmente-, ya que las prácticas simbólicas (y la iconografía es una de las más poderosas) contribuyen a formar la realidad y desempeñan un papel fundamental en la creación y re-creación de la ideología. Además, estas formas icono-verbales pueden proporcionar al alumnado universitario una visión de la realidad que ayude a transgredir las, demasiado frecuentemente, infranqueables fronteras entre disciplinas y a ser conscientes de la multiplicidad de interpretaciones que se puede hacer de la realidad y, como consecuencia, de la inestabilidad epistemológica. Las referencias filosóficas, políticas, estéticas, mitológicas o históricas que se pueden encontrar en cada uno de los emblemas obligan a los alumnos a manejar una gran cantidad de información, por lo que esta forma de aprehender la realidad y de acercarse a la cultura no puede ser sino beneficiosa. Al mismo tiempo, y como se ha destacado, en la emblemática se manifiestan de manera clara algunos de los rasgos esenciales del posmodernismo: la relación entre poder y saber o cómo la estructura del conocimiento se ve condicionada por el saber dogmático.

Por todo lo señalado hasta el momento, considero que la literatura emblemática es un género que puede, y debe, formar parte del discurso posmoderno en una gran variedad de disciplinas. Como afirmara Kerry Freedman, si se quiere educar desde el posmodernismo se debe hacer ver a los alumnos que la historia es inestable, no lineal, que es culturalmente integrada y altamente interpretativa (Efland y otros, 2003); y que "no existen referencias definitivas o absolutas, sino solamente soportes provisionales, frágiles y ambiguos, ubicados en el tiempo y en el espacio, en la historia, en la tradición" (Mèlich, 2008, 110). Con la adopción de la literatura emblemática como recurso didáctico no sólo se pueden cumplir estos objetivos, sino que, además, se puede revitalizar el utile dulci al que se refiriera el poeta Horacio en el Arte Poética; o, dicho con otras palabras, el aprender con placer como método.

\section{REFERENCIAS BIBLIOGRÁFICAS}

Amaral, R. (2013) Innovative Teaching Project. The Festina Lente project at the University of Jaén (Spain). Society for Emblem Studies Newsletter, 53, 23-25.

ARonowitz, S. y Giroux, A. (1991) Postmodern education: politics, culture and social. Minneapolis, University of Minnesota Press.

Ayuste, A. y Trilla, J. (2005) Pedagogías de la modernidad y discursos postmodernos sobre la educación. Revista de Educación, 336, 219-248.

BERnAT, A. (1998) La vida cotidiana en los libros de emblemas españoles, en EnTERRía, M. y CORDón, A. (eds.) Actas del Congreso Internacional de la Asociación Internacional Siglo de Oro. Alcalá de Henares, Servicio de Publicaciones de la Universidad de Alcalá de Henares, 237-249.

Carbonero, M. A. y Coromoto, J. (2006) Entrenamiento de alumnos de Educación Superior en estrategias de aprendizaje en matemáticas. Psicothema, 18 (3), 348-352. 
LA LITERATURA EMBLEMÁTICA EN UNA EDUCACIÓN UNIVERSITARIA DE CORTE POSMODERNO

CARR, W. (1995) Educación y democracia: ante el desafío postmoderno, en AA.VV. Volver a pensar la educación. Politica, sociedad y educación, vol. I. Madrid, Morata.

CHÁvez, H. (2006) Una aproximación metodológica interdisciplinaria en la educación artística. Discurso visual, 7. Consultado el 20 de julio de 2012.

http://discursovisual.cenart.gob.mx/dvwebne7/aportes/apochaves.htm.

Dale, R. y Robertson, S. (2007) Entrevista a Boaventura de Sousa Santos, en Bonal, X.; TARabini-Castellani, A. y Verger, A. (eds.) Globalización y Educación. Textos fundamentales. Madrid, Miño y Dávila Editores.

Eco, U. (1986) La estructura ausente. Introducción a la semiótica. Barcelona, Lumen.

EFland, A.; FreEdman, K. y STUHR, P. (2003) La educación en el arte posmoderno. Barcelona, Paidós.

Flecha, R. y TORTAJAdA, I. (1999) Retos y salidas educativas en la entrada de siglo, en IMBerNÓN, F. (ed.) La educación en el siglo XXI, los retos del futuro inmediato. Barcelona, Graó, 13-28.

FouCAult, M. (1991) Las palabras y las cosas. Madrid, Siglo Veintiuno.

FreIre, P. (1975) Pedagogía del oprimido. Madrid, Siglo XXI.

Gombrich, E. H. (1983) Imágenes simbólicas. Madrid, Alianza Editorial.

GORDON, M. (2007) What Makes Interdisciplinary Research Original? Integrative Scholarship Reconsidered. Oxford Review of Education, 33 (2), 195-209. http://dx.doi.org/10.1080/03054980701259642.

Guirault, G. (1550) Le premier libre des emblemes. Lyon, Balthazar Arnoullet.

LAUDO, W. (2011) La hipótesis de la pedagogía posmoderna. Educación, verdad y relativismo. Teoría de la Educación, 23 (2), 455-68.

Lotman, I. (1998) La semiosfera II. Semiótica de la cultura, del texto, de la conducta y del espacio. Madrid, Cátedra.

Lotman, I. (2000) La semiosfera III. Semiótica de las artes y de la cultura. Madrid, Cátedra.

LYOTARD, J. F. (1991) La condición posmoderna. Madrid, Cátedra.

Maravall, J. (1984) Estudios de Historia del pensamiento español. Serie tercera. El siglo del Barroco. Madrid, Cultura Hispánica.

MÈLICH, J. C. (2008) Antropología narrativa y educación. Teoría de la Educación, 20, 101-124.

Montalvo, J. (2011) Adivinanzas audiovisuales para ejercitar el pensamiento creativo infantil. Comunicar, 11 (36), 123-130. http://dx.doi.org/10.3916/C36-2011-03-03.

Moraes, M. C. (2005) O paradigma educacional emergente. Campinas, Papirus.

Morin, E. (1995) Introducción al pensamiento complejo. Barcelona, Editorial Gedisa.

MoRIN, E. (1999) La cabeza bien puesta. Repensar la reforma. Reforzar el pensamiento. Buenos Aires, Nueva Visión.

Nussbaum, M. (2012) Sin fines de lucro. Por qué la democracia necesita de las humanidades. Madrid, Katz.

PANOFSKY, E. (1989) Estudios sobre iconología. Madrid, Alianza Editorial.

Pérez, P. (2009) Creatividad e innovación: una destreza adquirible. Teoría de la Educación, 21 (1), 179-198.

Petrie, H. G. (1992) Interdisciplinary Education: Are We Faced with Insurmountable Opportunities? Review of Research in Education, 18, 299-333.

http://dx.doi.org/10.3102/0091732X018001299.

http://dx.doi.org/10.2307/1167302. 
RodríGUEZ De LA FloR, F. (1995) Emblemas. Lecturas de la imagen simbólica. Madrid, Alianza Editorial.

Rodríguez De la Flor, F. (1999) La Península metafísica. Arte, literatura y pensamiento en la España de la Contrarreforma. Madrid, Biblioteca Nueva.

RodrígueZ De LA Flor, F. (2002) Barroco. Representación e ideología en el mundo hispánico (1580-1680). Madrid, Cátedra.

RORTY, R. (1993) Deconstrucción y circunvención, en RORTY, R. Ensayos sobre Heidegger y otros pensadores contemporáneos. Escritos filosóficos 2. Barcelona, Paidós, 125-152. Consultado el 30 de julio de 2012.

http://www.jacquesderrida.com.ar/comentarios/circunvencion.htm.

Sebastián, S. (1995) Emblemática e Historia del Arte. Madrid, Cátedra.

SOlORÇANO Y PEREYRA, J. (1658-60) Emblemas regio políticos. Valencia, Bernardo Noguès.

Terrén, E. (1997) Posmodernidad y educación. Política y Sociedad, 24, 121-139.

Yilmaz, K. (2010) Postmodernism and its Challenge to the Discipline of History: Implications for History Education. Educational Philosophy and Theory, 42 (7), 779-795. http://dx.doi.org/10.1111/j.1469-5812.2009.00525.x. 